\title{
Privatization in Canada? Not Yet
}

\author{
Anthony Bozzo
}

From 1975 to 2005, the proportion of medical expenses financed privately grew by $25 \%$ (1). In 2005, the Canadian Supreme Court issued a ruling in Quebec that legalized private delivery of core medical services (2). Shortly thereafter, the CMA endorsed a motion supporting the right to have private insurance for core medical services (3). Dr Brian Day, head of the CMA from 2007-2008, is litigating the unconstitutionality of Medicare within the British Columbia Supreme Court with the goal of increasing both private funding and private delivery of medical services (4). These facts could lead one to believe that medical practice within Canada is on the fast track to privatization. However, in this paper I will argue that despite certain suggestive initiatives, the privatization of hospitals and core medical services is unlikely in the foreseeable future and therefore presents limited implications for my future practice.

Canada's position on universal healthcare - the provision of core hospital and physician services independent of social status, age, gender, or race, was a reflection of our value of the equality of all citizens. Today, the public healthcare system, which has stood for 50 years, is under attack not due to changes in Canadian ideology, but for other reasons: efficiency and economy. A mixed publicprivate system is being touted as advantageous for the patient by lessening patient queues within the public system $(2,5)$. There is already an increased private presence within our medical system, and this has occurred slowly and almost inconspicuously in three primary ways.

Firstly, within the publicly funded portion of Quebec healthcare, private companies have been allowed to compete to be the providers of certain goods (4). The government's aim in this regard was to generate lower end prices by increasing

*To whom correspondence should be addressed:

Anthony Bozzo

anthony.bozzo@mail.mcgill.ca competition. This is one important example of the difference between public funding and public delivery of healthcare. Secondly, private interests have gained lasting footholds in our health care system through a change in the way large-scale health projects are financed. Whereas governments used to pay up-front for the construction of hospitals, provincial governments of Quebec, Ontario, and BC have all entered public-private partnerships (P3s) in which a private team of construction companies and project managers assume the building costs while governments provide ongoing payments in the future. The P3 financiers are then usually given lasting decision making power normally exclusive to hospital board members (4). Thirdly, and perhaps most significant, is the ruling in the Chaoulli case of 2005. After a patient's life was put in jeopardy while he waited futilely within the public system for a hip replacement, the Supreme Court ruled that it was a violation of Quebec's charter of rights to refuse this patient's private operation elsewhere $(5,6)$. Since this ruling, patients have been able, for the first time ever, to seek private insurance for core hospital services, but only if those publicly funded services fail to meet certain medical benchmarks.

Today, only around $70 \%$ of Canadian health expenses are publicly funded. However, public funding of hospital care and physician services has always been close to $100 \%$ and it is newly emerging health care categories such as invitro fertilization and cosmetic surgeries, services rendered outside of hospitals (long-term home care, ambulances), and prescription drugs which are mostly, or in some cases completely, financed by private funds. Furthermore, while the publicly financed proportion dropped from $75.6 \%$ in 1975 to $69.6 \%$ in 2005 , it has remained steady at that level since then with the public percentage being 70.6 in 2007 and 70.2 in 2009 (1,4). In light of the aforementioned events, will Canada continue on the trend towards privatization?

While some physicians in high positions have been accused of supporting private healthcare 
out of self-interest (higher salaries, etc) (6), the requisite government support and the legislation required for shifting to privatization will only occur if private medicine is shown to improve patient's access to care. The question then becomes, has private care been shown to improve patient outcome in the countries that have it and lessen wait times in public hospitals in countries with mixed publicprivate healthcare?

Tellingly, studies in Australia, Britain, and New Zealand have found that having a parallel private system does not reduce or eliminate wait times in a public system $(7,8)$. In fact, areas with higher rates of private insurance were correlated with higher wait times in their public sectors (7). Perhaps most striking is the finding in several countries that patients in the private system do not have a better quality of life or live longer than patients in the public system $(9,10)$. A similar trend is seen when observing our neighbors to the south: the private US system's per capita spending $(\$ 5635)$ is almost double the largely public Canadian spending (\$3003) without any significant advantages in patient outcome or quality of life $(5,7)$.

There is also a lack of evidence indicating clear benefits in the use of P3s in building hospitals. While data from the UK indicates that P3 projects are more often completed on time and within budget, this efficiency was shown to come at the expense of facility "quality" and design flexibility. Oftentimes the layout of the facilities was said to be optimal for the construction team rather than for the patients that would eventually take up residence4. Furthermore, P3 contracts are typically finalized many years in advance and the government would incur severe penalties for any changes, thus limiting the potential use of new technologies (4). The local implications of our new MUHC superhospital being a P3 with both SNC-Lavalin and a British firm are beyond the scope of this paper.

It is worth noting that the "most controversial Supreme Court of Canada decision to date"4 (Chaoulli) did not open up the option of private practice to droves of Canadian physicians. For one, the ruling within Quebec could not be readily applied to other provinces due to slightly different wording of the relevant clause within their respective charters. Within Quebec, the only noticeable short term effect was a positive outcome within the public system as the government adopted strict benchmarks of a six month maximum wait for hip replacements and a provision that the government would pay for treatment outside the province if wait times exceeded this (5).

Furthermore, there are signs that governments are beginning to more effectively police Canadian physicians who try to charge patients for core services - a practice outlawed by the Canada Health Act. The most prominent example is the auditing of the practice of $\mathrm{Dr}$ Brian Day, a former CMA head, by the British Columbia Medical Services Commission. They are investigating this vocal proponent of medical privatization for unlawful billing practices such as charging patients for core services - a clear violation of the Medicare Protection Act (4). Taken together, there are signs that our government will not passively accept private practice while the legislation supports public medicine.

Today, fewer than $1 \%(158 / 16000)$ of Quebec physicians are practicing privately (1). Doing so would require opting out of the public system entirely and they would therefore not be assured of any revenue. This is one of many obstacles which has deterred physicians from working privately in the past and will continue to do so until core services become privatized, therefore providing a larger potential pool of patients. I believe that until there is evidence to back the claim that a private system will strengthen the existing public system, the CHA ban on private coverage of core services will not be amended and will consequently continue to limit private medical practices in Canada to fringe specialties like IVF and cosmetic surgery.

Public funding in Canada has remained stable at $70 \%$ since 2005 and the Chaoulli ruling did not result in the introduction of mass private healthcare in Quebec. There is a lack of the requisite evidence that a mixed public-private system would reduce wait times and improve patient outcomes needed to push significant changes at the government level. While private financing may continue to increase in fringe medical markets such as IVF and cosmetic surgery, there is no indication that the core services offered by physicians will be privatized in Canada anytime soon. As such, only medical students considering a specialty choice in one of the aforementioned narrow fields are likely to encounter a scenario in which a privatized practice is an option.

\section{REFERENCES}

1. Di Matteo L. Policy Choice or Economic Fundamentals: What drives the public-private health expenditure balance in Canada? Health Economics Policy and Law (2009): 4: 29-53 
2. Bhatia S, Natsheh A. Should Canadian Physicians Support parallel private health care? CMAJ (2005) 173: 8 pp 901-902

3. Sibbald B. CMA Okays private health care for waiting patients. CMAJ 173 (6): 585

4. Flood C, Thomas B. Blurring of the public/private Divide: The Canadian Chapter. European Journal of Health Law. (2010) 257-278

5. Steinbrook R. Private Health Care in Canada. NEJM (2006) 354:16 pp 1661-166

6. Hoyt B. Public vs Private: The Medical Resident Perspective. CMAJ (2005) 173: 8 pp 898-899
7. Tuohy C, Flood C, Stabile M. How does private finance affect public health care systems: evidence from OCED nations. J Health Polit Policy Law (2004) 29(3): 359-396

8. Duckett SJ. Private care and public waiting. Australian Health Review (2005) 29: 1

9. Devereaux PJ, Choi PT, et al. A systematic meta analysis of studies comparing mortality rates of private for profit and private not for profit hospitals. CMAJ (2002) 166(11): 1399-1406

10. Himmelstein DU, Woolhandler S, et al. Quality of care in investor owned vs not for profit HMOs. JAMA (1999) 282(2): 159 